\title{
Effects of day of gestation and feeding regimen in Holstein $\times$ Gyr cows: III. Placental adaptations and placentome gene expression
}

\author{
P. P. Rotta, ${ }^{*} \dagger^{1}$ S. C. Valadares Filho, ${ }^{*}$ T. R. S. Gionbelli, ${ }^{*}$ L. F. Costa e Silva, ${ }^{*} \dagger$ T. E. Engle, $\dagger$ M. I. Marcondes, ${ }^{*}$ \\ S. E. F. Guimarães, ${ }^{\star}$ C. S. Nascimento, ${ }^{*}$ B. C. Carvalho,ł F. A. S. Silva, ${ }^{*}$ and J. R. S. Oliveira* \\ *Department of Animal Science, Universidade Federal de Viçosa, Viçosa, Brazil 36571-000 \\ †Department of Animal Science, Colorado State University, Fort Collins 80523 \\ ‡Embrapa Gado de Leite, Juiz de Fora, Brazil 36038-330
}

\section{ABSTRACT}

This study investigated the influence of day of gestation (DG) and feeding regimens (FR) on the expression of genes responsible for placenta development, nutrient transfer, and angiogenic factors in Holstein $\times \mathrm{Gyr}$ cows. Forty pregnant multiparous Holstein $\times$ Gyr cows with an average initial body weight of $482 \pm 10.8 \mathrm{~kg}$ and an initial age of $5 \pm 0.8 \mathrm{yr}$ were allocated to 1 of 2 FR: ad libitum $(\mathrm{AL} ; \mathrm{n}=20)$ or maintenance level $(\mathrm{ML} ; \mathrm{n}=20)$. Maintenance level was considered to be $1.15 \%$ of body weight (dry matter basis) and met $100 \%$ of the net energy requirements and AL provided 190\% of the total net energy requirements. Cows were slaughtered at 4 DG: 139, 199, 241, and 268 d. After the cows were slaughtered, the placenta and uterus were separated and weighed. Caruncles and cotyledons were individually separated, counted, and weighed. Placenta expressed as kilograms and grams per kilogram of empty body weight (EBW) was heavier in ML- than in AL-fed cows at $268 \mathrm{~d}$ of gestation. Placenta expressed as kilograms and grams per kilogram of EBW was the lightest at $139 \mathrm{~d}$ of gestation, and the greatest mass was observed at $268 \mathrm{~d}$ in ML-fed cows. However, in AL-fed cows, the heaviest placenta expressed as grams per kilogram of EBW was observed from 199 d of gestation. Placentomes expressed as grams per kilogram of EBW were heavier in ML-fed cows during gestation, and the number of placentomes was greater in ML-fed cows at $268 \mathrm{~d}$ of gestation. We observed that IGFR1 and IGFR2 were involved in placenta adaptations when ML was provided, as their expression in placentome cells was greater in ML-fed cows at $268 \mathrm{~d}$ of gestation. The genes responsible for angiogenesis were also greater in ML-fed cows: VEGFA, GUCY1B3, HIFA, FGF2, and $N O S 3$ were altered by $\mathrm{FR}$ and DG interaction and they were greater in ML-fed cows at $268 \mathrm{~d}$ of gestation. In

Received April 24, 2014.

Accepted January 11, 2015.

${ }^{1}$ Corresponding author: polyana.rotta@ufv.br addition, $V E G F B$ and $A N G P T 2$ did not show interactions between FR and DG, but they were greater in ML-fed cows. Thus, we suggest that the placenta from an ML-fed cow develops adaptations to the reduced nutrient supply by altering its structure and gene expression, thereby developing mechanisms for potential increased nutrient transfer efficiency to the fetus.

Key words: gravid uterus, insulin-like growth factor receptor (IGFR), IGFR1, IGFR2, placentome

\section{INTRODUCTION}

The majority of mammalian livestock for animal production spend 35 to $40 \%$ of their life within the uterus being nourished solely by the placenta (Vonnahme et al., 2013). Thus, it is especially important to understand the influences of maternal nutrition on placental growth, development, and gene expression, because they directly affect fetal growth (Vonnahme et al., 2013). The relationship between maternal nutrient intake during pregnancy and growth of the fetus is extremely important for determining pregnancy success and the life-long health and productivity of an individual (Godfrey and Barker, 2000; Godfrey, 2002). Because profitability in the livestock industry depends upon efficiency of production characteristics such as growth and development after birth, the precursor of efficiency - fetal growth - must be optimal (Redmer et al., 2004; Zhu et al., 2014).

The size and nutrient transfer capacity of the placenta play a central role in determining the prenatal growth trajectory of the fetus, and hence, directly influences birth weight. Transplacental exchange is dependent upon uterine and umbilical blood flow, and these blood flows are in turn largely dependent on adequate vascularization of the placenta (Redmer et al., 2004). Ford (2000) stated that in sheep there are 70 to 120 placentomes, and each one is composed of fetal and maternal components. Cotyledons are tufts of chorionic villi that develop adjacent to the uterine caruncle on the uterine wall, and interdigitate with corresponding 
crypts of the uterine caruncle to form the placentome units (Ford, 2000). However, no study has been conducted to evaluate the effect of day of gestation (DG) and feeding regimen (FR) on placentome units in Holstein $\times$ Gyr cows.

Several studies (Vonnahme et al., 2003; Laviola et al., 2005; Zhu et al., 2007) have shown that maternal nutrient restriction alters placenta function, and hence, the fetal nutrient supply line, but little is known of the effects of maternal feed restriction on the expression of genes that regulate placenta growth and function in dairy cows. Both insulin-like growth factors have a key role in regulating feto-placental growth throughout gestation (Fowden, 2003). Thus, a difference in their gene expression receptors may significantly alter the regulation of placenta and fetal growth and development. Angiogenesis is the formation of new vascular beds, and it is a critical process for the growth and development of all tissues, including the placenta in ruminants (Reynolds and Redmer, 1992; Borowicz et al., 2007). The search for potential regulators of angiogenesis has led to the identification of the major angiogenic factors (Shalaby et al., 1995; Carmeliet et al., 1996; Ferrara et al., 1996). These major angiogenic growth factors in ruminants include the vascular endothelial growth factor family and its major transmembrane tyrosine kinase receptors (FLT1 and KDR), FGF2, angiopoietins, and their tyrosine kinase receptor (TEK), NOS3, the NO receptor, GUCY1B3, and $H I F 1 A$.

Thus, our hypothesis is that placentas of cows fed a maintenance level (ML) diet are more efficient in transferring nutrients to the fetus than cows fed ad libitum $(\mathbf{A L})$. This efficiency may be related to greater expression of genes that are involved in nutrient transfer and angiogenesis in the placenta. Our objectives in this study were to evaluate the placenta characteristics and expression of the genes VEGFA, VEGFB, ANGPT2, FGF2, NOS3, IGFR1, IGFR2, GUGY1B3, and HIF1A in placentome cells of dairy cows fed AL or ML at different DG.

\section{MATERIALS AND METHODS}

All animal care and handling procedures were approved by the Animal Care and Use Committee of the Department of Animal Science of the Universidade Federal de Viçosa, Viçosa, Minas Gerais, Brazil, before initiation of the experiment.

\section{Animals and Management}

The animals used in this present experiment such as the management adopted is described in a companion paper (Rotta et al., 2015b). However, a brief descrip- tion is provided as follows: 40 multiparous dry Holstein $\times$ Gyr cows with an average initial BW of $482 \pm 10.8$ $\mathrm{kg}$ and age of $5 \pm 0.8 \mathrm{yr}$ were allocated to 1 of $2 \mathrm{FR}$ : AL $(\mathrm{n}=20)$ or ML $(\mathrm{n}=20)$. The average age of the cows used in this experiment was chose because it represents the average age of cows raised in Brazil (IBGE, 2009). Maintenance level was considered to be $1.15 \%$ of BW (in DM basis). The average milk production of the last lactation was $12.5 \pm 1.36 \mathrm{~L} / \mathrm{d}$ for AL-fed cows and 13.4 $\pm 1.20 \mathrm{~L} / \mathrm{d}$ for ML-fed cows. The average number of lactations was $2.9 \pm 0.25$ and $3.0 \pm 0.25$ for AL-fed and ML-fed cows, respectively. To evaluate the effects of different DG, pregnant cows were slaughtered at 4 DG. Each FR group was randomly divided into 4 groups, with 5 cows from AL and 5 cows from ML slaughtered at 139, 199, 241, and $268 \mathrm{~d}$ of gestation. Cows were fed a corn silage and concentrate-based diet at a ratio of 93:7 (on a DM basis) as a TMR twice daily, with $60 \%$ in the morning and $40 \%$ in the afternoon.

\section{Slaughter and Laboratory Analyses}

Preharvest handling was in accordance with good animal welfare practices, and slaughtering procedures followed the Sanitary and Industrial Inspection Regulation for Animal Origin Products (Brasil, 1997). The slaughters were performed on the same calendar day for each DG.

Before slaughter, feed was withheld overnight, but cows had ad libitum access to water. Cows were slaughtered at Universidade Federal de Viçosa by captive bolt stunning followed by exsanguination. After slaughter, the gravid uterus was removed and weighed; then, the surface area of 3 placentomes was measured and tissue from 1 placentome was sampled. Placentome tissue samples were collected in RNAHolder (BioAgency, São Paulo, SP, Brazil) and stored at $-20^{\circ} \mathrm{C}$ until the RNA extraction procedure.

The placenta and uterus were separated and weighed. Amniotic liquid was also weighed. Caruncles and cotyledons were individually separated, counted, and weighed. The placenta and uterus were individually ground and a homogenized sample was created and maintained at $-80^{\circ} \mathrm{C}$ until further analysis. Placenta and uterus were analyzed for $\mathrm{DM}$ and $\mathrm{N}$ concentrations (AOAC International, 2000; method 934.01 for DM and 981.10 for $\mathrm{N})$.

\section{Real-Time Transcription PCR Analysis}

Total RNA was isolated from $100 \mathrm{mg}$ of placentome tissue using the reagent Trizol (Invitrogen, Carlsbad, CA). The total RNA was resuspended in RNase-free ultrapure water and stored at $-70^{\circ} \mathrm{C}$ until further use. 
Concentrations of RNA were checked by NanoVue Plus Spectrophotometer (GE Healthcare, Piscataway, NJ) with an optimal optical density ratio at 260:280 nm between 1.8 and 2.1. Intact $28 \mathrm{~S}$ and $18 \mathrm{~S}$ rRNA subunit integrity was assessed by agarose gel electrophoresis to detect degradations of the RNA.

One microgram of total RNA was treated with RNase-free DNAase I (Invitrogen Life Technologies) to remove any contaminating DNA. Reverse transcription was performed using GoScript Reverse Transcription System (Promega, Madison, WI) and oligo (dT) primers (Invitrogen). Then, $80 \mu \mathrm{L}$ of sterile autoclaved nuclease-free water (Invitrogen, Grand Island, NY) was added to the reverse transcription product. All reverse transcriptions and no-template controls were run at the same time.

Quantitative real-time PCR reactions were performed in triplicate using SYBR Green detection with GoTaq PCR Master Mix (Promega) and gene-specific primers. The gene target and reference sequence was recovered from nucleotide sequences obtained from the GenBank database. The following genes were evaluated: VEGFA, VEGFB, FGF2, ANGPT2, NOS3, GUCY1B3, HIF1A, IGFR1, and IGFR2. These sequences were used to construct primers by the PrimerQuest program provided by Integrated DNA Technologies Inc. (Coralville, IA) and are summarized in Table 1.

Before performing real-time PCR, part of the reverse transcription product was diluted, pooled, and then diluted serially to construct standard curves for optimal PCR conditions and to calculate PCR efficiency. For this purpose, 4 volumes of cDNA $(0.5,1.0,2.0$, and $4.0 \mathrm{nM})$ and 4 primer dilutions (100, 200, 400, and 800 $\mathrm{n} M$ ) were tested. The following experimental protocol was used: quantification program consisting of 1 cycle of $95^{\circ} \mathrm{C}$ for $10 \mathrm{~min}, 40$ cycles of $95^{\circ} \mathrm{C}$ for $10 \mathrm{~s}$, and $15 \mathrm{~s}$ at $60^{\circ} \mathrm{C}$. After 40 cycles of amplification, an additional step with a gradual increase in temperature of 60 to $95^{\circ} \mathrm{C}$ was used to obtain the dissociation curve. The amplification of target and reference genes was performed in different wells and in duplicate (Livak and Schmittigen, 2001). The PCR amplification efficiencies $(E)$ were calculated for each reference gene assay using the formula $E=10^{(-1 / \text { slope })} \times 100$ (Pfaffl, 2001) and are presented in Table 2. The dissociation curves showed no peaks corresponding to primer dimers or nonspecific products for any of the target or reference genes, confirming that specific gene amplification was achieved.

After analysis of efficiency, the optimal annealing temperature and primer concentration were used to perform PCR. All reactions were performed on ABI Prism 7300 sequence detection system (Applied Biosystems, Foster City, CA) and cycle threshold values were exported into Excel files (Microsoft Corp., Redmond,

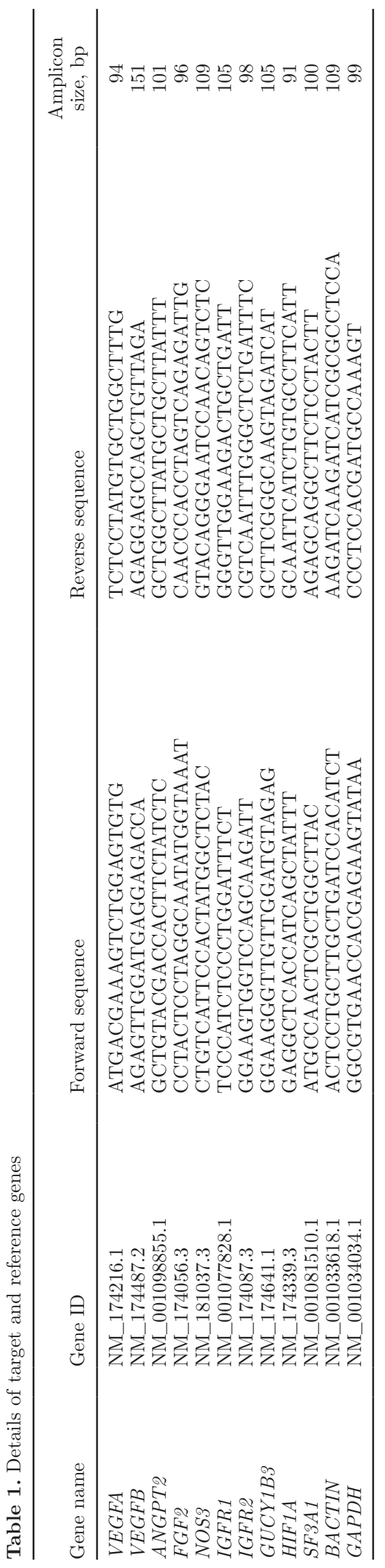


Table 2. Polymerase chain reaction amplification efficiencies for each reference gene

\begin{tabular}{lcccc}
\hline Gene & $\begin{array}{c}\text { Angular } \\
\text { coefficient }\end{array}$ & $\mathrm{R}^{2}$ & Efficiency, $\%$ & Concentration, $\mathrm{n} M$ \\
\hline VEGFA & -3.3136 & 0.9999 & 100.35 & 200 \\
VEGFB & -3.2837 & 0.9987 & 101.62 & 200 \\
ANGPT2 & -3.4631 & 0.9891 & 95.43 & 800 \\
FGF2 & -3.3605 & 0.9995 & 98.42 & 800 \\
NOS3 & -3.2890 & 0.9933 & 101.39 & 200 \\
IGFR1 & -3.3086 & 0.9592 & 100.56 & 400 \\
IGFR2 & -3.2963 & 0.9995 & 101.08 & 400 \\
GUCY1B3 & -3.2156 & 0.9991 & 104.64 & 200 \\
HIFA & -3.4744 & 0.9853 & 96.01 & 100 \\
SF3A1 & -3.2605 & 0.9964 & 102.63 & 400 \\
ACTB & -3.3877 & 0.9958 & 97.33 & \\
GAPDH & -3.3538 & 0.9987 & 98.69 &
\end{tabular}

WA) for further analysis. The mean of the threshold cycle, defined as the fractional cycle number at which the fluorescence passes the fixed threshold, was determined using manual threshold settings. The level of expression of each target gene was normalized by dividing the relative quantity by averaged quantities of the 3 reference genes (Vandesompele et al., 2003). The normalization factor was calculated as the geometric mean of $\beta$-actin $(A C T B), G A P D H$, and splicing factor 3a, subunit 1 (SF3A1) for each sample.

\section{Data Analysis}

Before performing the statistical analysis, we tested the normality of variables and they were normally distributed. The experiment was analyzed as a $4 \times 2$ factorial design by using the MIXED procedure (SAS Inst. Inc., Cary, NC). Day of gestation, maternal FR, fetal sex, and their interaction were included as fixed effects in the model. Means were separated using the LSMEANS option of SAS and were considered significant when $P \leq 0.10$. In the absence of maternal $\mathrm{FR} \times$ DG interaction, main effects are reported; otherwise, interaction means are discussed.

\section{RESULTS}

\section{Utero and Placenta Characteristics}

We did not observe a difference $(P=0.31)$ in the mass of gravid uterus between AL- and ML-fed cows (Table 3). However, when expressed as grams per kilogram of empty body weight (EBW), a difference $(P$ $=0.01$ ) was observed for the gravid uterus according to the different FR that were studied. Maintenance-fed cows had a heavier $(P=0.01)$ gravid uterus expressed as grams per kilogram of EBW than AL-fed cows. Considering that fetal weight was similar between FR (AL:
$17.0 \pm 0.75$ and ML: $15.9 \pm 0.69 \mathrm{~kg}$ ), the components responsible for this increase were the uterus, placenta, and fetal fluids, which were heavier $(P=0.04)$ in MLfed cows.

As expected, DG affected uterine mass (Table 3). Uterine mass increased $(P<0.01)$ as gestation progressed from 139 to $268 \mathrm{~d}$ of gestation. No difference $(P=0.34)$ was observed in uterine mass between ALand ML-fed cows (Table 3). Figure 1 illustrates the relationship between the mass of uterus and fetus during gestation. We observed that during gestation, the uterine mass in AL- and ML-fed cows was similar $(P=$ $0.34)$. Thus, no alteration occurred in the uterine mass based on FR evaluated in this study. However, placenta mass was altered $(P<0.01)$ by FR. Figure 2 shows the difference in placenta mass at $268 \mathrm{~d}$ of gestation between AL- and ML-fed cows. At 268 d of gestation, placenta mass was greater in ML- than in AL-fed cows; it was 1.63 times greater in ML-fed cows. Thus, we can assume that because fetal mass was not altered by FR, ML-fed cows may have had placental adaptations to be more efficient in transferring nutrients to the fetus.

Another important change caused by FR concerned fetal liquids expressed as grams per kilogram of EBW. Greater $(P=0.04)$ fetal liquid mass was found in MLthan AL-fed cows. Fetal liquid mass was similar $(P=$ 0.77 ) at 139,199 , and $241 \mathrm{~d}$ of gestation. However, at d 268, we observed the greatest mass, being 1.88 times greater than the fetal liquid mass from d 241.

The mass of caruncles and cotyledons were similar $(P=0.20)$ according to the evaluated FR (Table 4). However, when expressed as grams per kilogram of EBW, both caruncles and cotyledons were heavier $(P$ $=0.07)$ in ML-fed cows. Because placentomes are the sum of caruncles and cotyledons, the same result was observed for placentomes. Maintenance-fed cows had greater $(P=0.02)$ placentome mass expressed as grams per kilogram of EBW than AL-fed cows. 


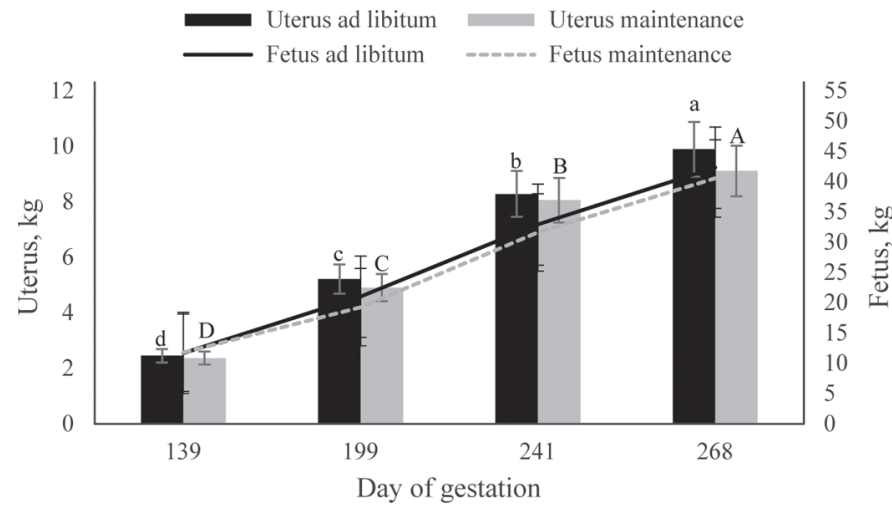

Figure 1. Relation between mass of uterus and fetus during gestation in Holstein $\times$ Gyr cows. Results are means \pm SEM. Different lowercase letters are different at $P \leq 0.10$ for ad libitum diets during gestation; different uppercase letters are different at $P \leq 0.10$ for maintenance diets during gestation.

The mass of caruncles, cotyledons, and placentomes were different $(P=0.07)$ according to DG (Table 4$)$. For caruncles and placentomes, the greatest masses occurred at 241 and $268 \mathrm{~d}$ of gestation, and the lowest mass was at d 139. However, when considering cotyledons, the heaviest mass was at $\mathrm{d} 268$.

Placentome units presented with an interaction $(P<$ 0.01) between FR and DG (Figure 3). At 139 and 199 d of gestation, no difference $(P=0.69)$ was observed between FR and placentome units. However, at 241 and $268 \mathrm{~d}$ of gestation, the greatest $(P<0.01)$ values were observed in ML-fed cows. Moreover, placentome units of AL-fed cows differed by DG; at d 139, the lowest value was observed, whereas no difference $(P=0.66)$ occurred at 199, 241, and $268 \mathrm{~d}$ of gestation (Figure 3).

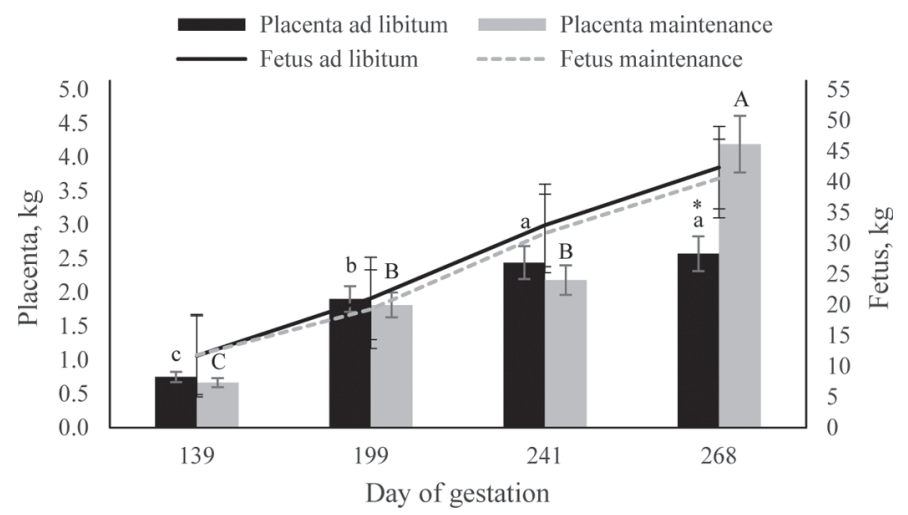

Figure 2. Relation between mass of placenta and fetus during gestation in Holstein $\times$ Gyr cows. Results are means \pm SEM. Different lowercase letters are different at $P \leq 0.10$ for ad libitum diets during gestation; different uppercase letters are different at $P \leq 0.10$ for maintenance diets during gestation. *Difference between ad libitum and maintenance diets at $P \leq 0.10$.

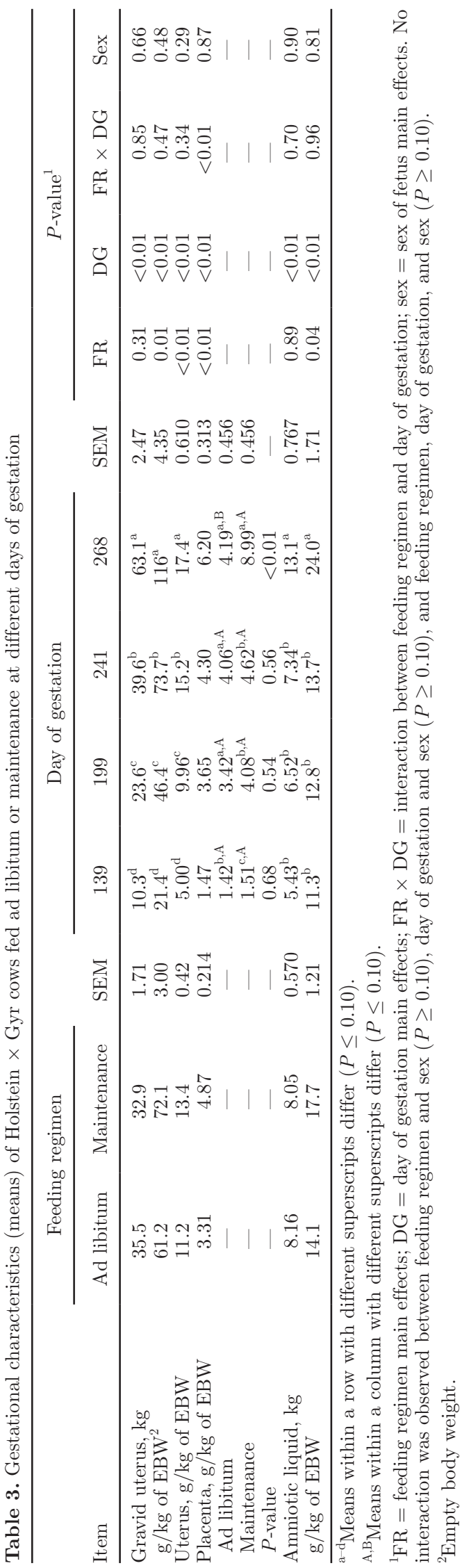



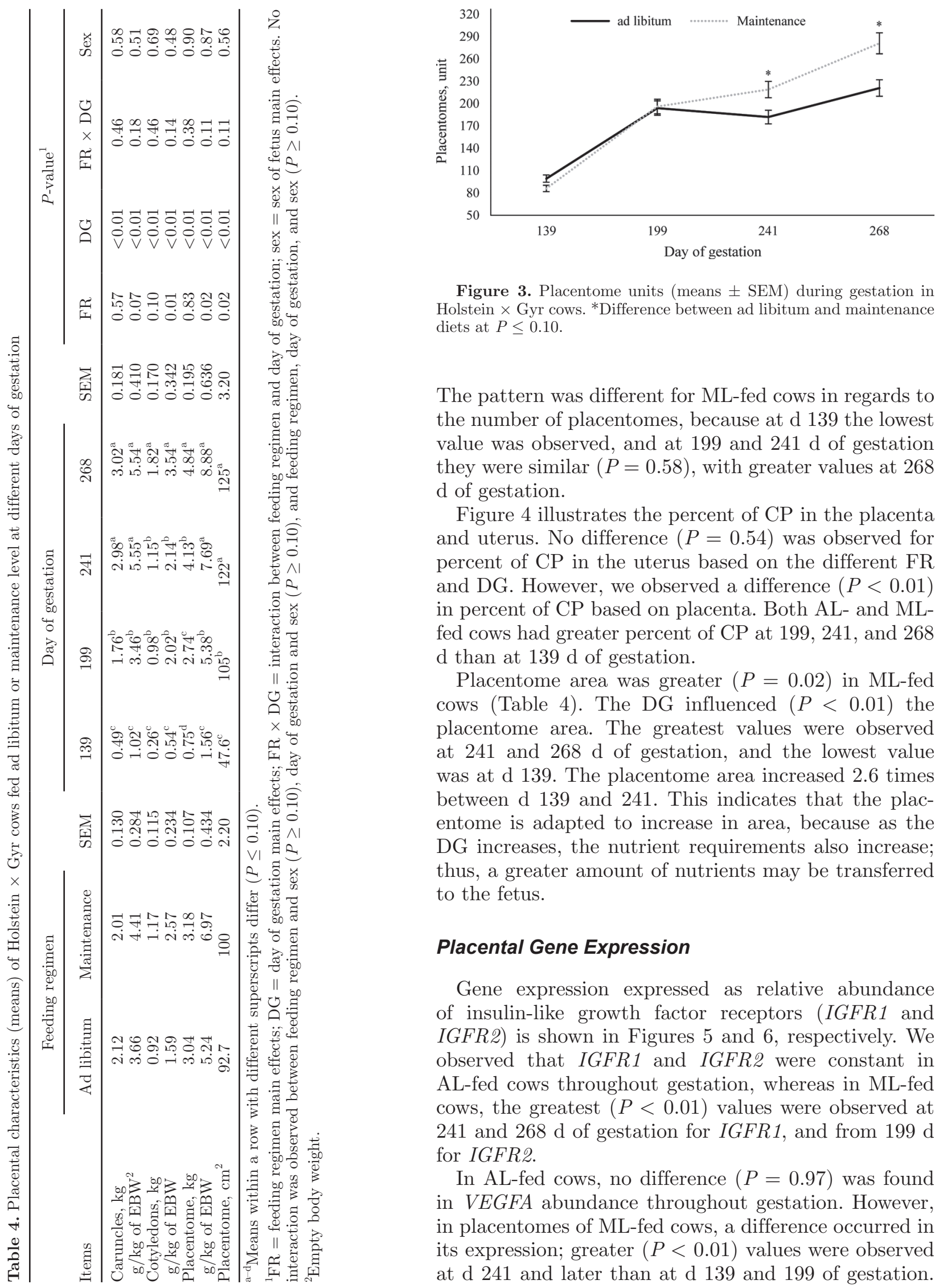

Figure 3. Placentome units (means \pm SEM) during gestation in Holstein $\times$ Gyr cows. ${ }^{*}$ Difference between ad libitum and maintenance diets at $P \leq 0.10$.

The pattern was different for ML-fed cows in regards to the number of placentomes, because at d 139 the lowest value was observed, and at 199 and $241 \mathrm{~d}$ of gestation they were similar $(P=0.58)$, with greater values at 268 $\mathrm{d}$ of gestation.

Figure 4 illustrates the percent of $\mathrm{CP}$ in the placenta and uterus. No difference $(P=0.54)$ was observed for percent of $\mathrm{CP}$ in the uterus based on the different FR and DG. However, we observed a difference $(P<0.01)$ in percent of CP based on placenta. Both AL- and MLfed cows had greater percent of CP at 199, 241, and 268 d than at $139 \mathrm{~d}$ of gestation.

Placentome area was greater $(P=0.02)$ in ML-fed cows (Table 4$)$. The DG influenced $(P<0.01)$ the placentome area. The greatest values were observed at 241 and 268 d of gestation, and the lowest value was at $\mathrm{d} 139$. The placentome area increased 2.6 times between $\mathrm{d} 139$ and 241. This indicates that the placentome is adapted to increase in area, because as the DG increases, the nutrient requirements also increase; thus, a greater amount of nutrients may be transferred to the fetus.

\section{Placental Gene Expression}

Gene expression expressed as relative abundance of insulin-like growth factor receptors (IGFR1 and IGFR2) is shown in Figures 5 and 6, respectively. We observed that IGFR1 and IGFR2 were constant in AL-fed cows throughout gestation, whereas in ML-fed cows, the greatest $(P<0.01)$ values were observed at 241 and $268 \mathrm{~d}$ of gestation for IGFR1, and from $199 \mathrm{~d}$ for IGFR2.

In AL-fed cows, no difference $(P=0.97)$ was found in VEGFA abundance throughout gestation. However, in placentomes of ML-fed cows, a difference occurred in its expression; greater $(P<0.01)$ values were observed at d 241 and later than at d 139 and 199 of gestation. 

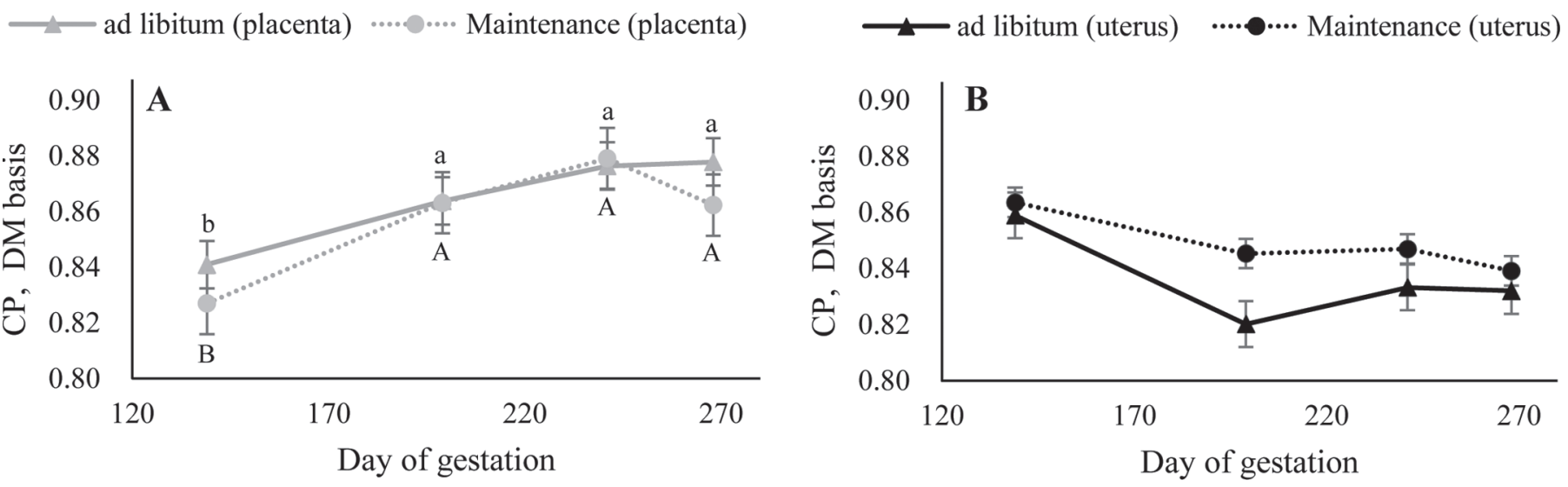

Figure 4. Crude protein concentration (means \pm SEM) in placenta (A) and uterus (B) in Holstein $\times$ Gyr cows at different days of gestation. Different lowercase letters are different at $P \leq 0.10$ for ad libitum diets during gestation; different uppercase letters are different at $P \leq 0.10$ for maintenance diets during gestation. No difference $(P \geq 0.10)$ was observed for protein concentration in the uterus.

Moreover, greater values $(P<0.01)$ of $V E G F A$ were observed in ML-fed cows than AL-fed cows at 241 and 268 d of gestation (Table 5).

In contrast, $V E G F B$ was not influenced $(P=0.49)$ by DG, and similar values were found throughout gestation. However, we observed that FR affected $(P<$ $0.01)$ its expression. The greatest $(P<0.01)$ value was found in ML-fed cows.

As observed for $V E G F B$, no difference $(P=0.12)$ was detected for ANGPT2 in the studied DG. However, we observed that ML-fed cows had greater $(P=0.06)$ values for ANGPT2 than AL-fed cows. For FGF2 and NOS3, similar $(P<0.01)$ values were observed during gestation in AL-fed cows, but for ML-fed cows, DG affected their expression, and the lowest value was found at d 139 of gestation. Ad libitum and maintenance-fed cows differed $(P<0.01)$ in FGF2 and NOS3 at 199,

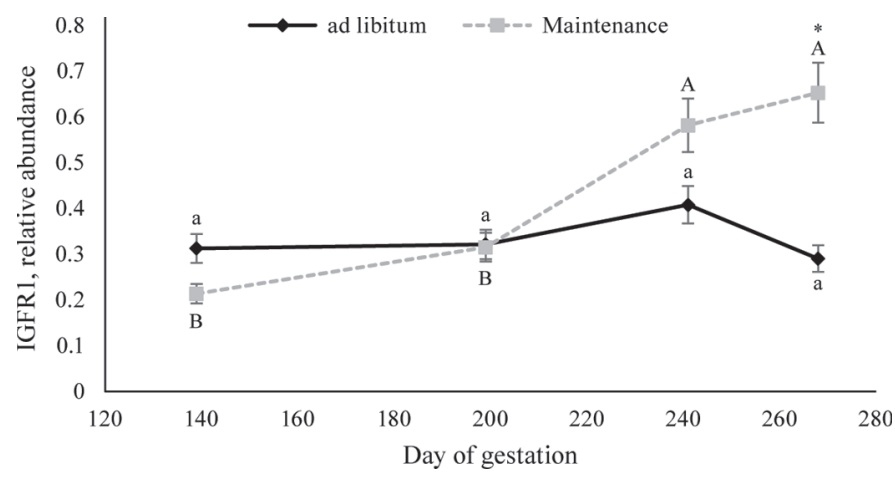

Figure 5. Relative abundance (means \pm SEM) of insulin-like growth factor receptor 1 (IGFR1) during gestation in Holstein $\times$ Gyr cows. ${ }^{*}$ Different at $P \leq 0.10$. Different lowercase letters are different at $P \leq 0.10$ for ad libitum diets during gestation; different uppercase letters are different at $P \leq 0.10$ for maintenance diets during gestation.
241 , and $268 \mathrm{~d}$ of gestation, with the greatest values observed in ML-fed cows.

Soluble guanylate cyclase ( $G U C Y 1 B 3)$ was constant $(P=0.65)$ throughout gestation in AL-fed cows (Table $5)$. However, in ML-fed cows, the greatest $(P<0.01)$ values were observed at 241 and $268 \mathrm{~d}$ of gestation, but no difference $(P=0.39)$ was observed between 199 and $268 \mathrm{~d}$ of gestation. At 241 and $268 \mathrm{~d}$ of gestation, MLfed cows had greater $(P<0.01)$ values for $G U C Y 1 B 3$ than did AL-fed cows.

Hypoxia inducible factor-1 $(H I F 1 A)$ was similar $(P$ $=0.40)$ in AL-fed cows throughout gestation, but for ML-fed cows, it differed $(P<0.01)$ among DG. At 241 and $268 \mathrm{~d}$ of gestation, the greatest $(P<0.01)$ values were observed for HIF1A. Moreover, FR differed at 241 and $268 \mathrm{~d}$ of gestation, with ML-fed cows presenting the greatest values for HIFA.

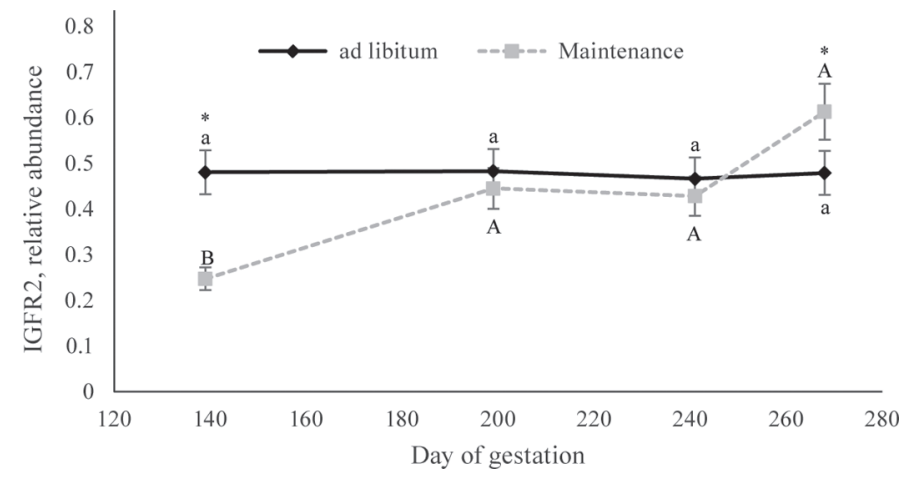

Figure 6. Relative abundance (means \pm SEM) of insulin-like growth factor receptor 2 (IGFR2) during gestation in Holstein $\times$ Gyr cows. *Different at $P \leq 0.10$. Different lowercase letters are different at $P \leq 0.10$ for ad libitum diets during gestation; different uppercase letters are different at $P \leq 0.10$ for maintenance diets during gestation. 
Table 5. Gene expression (relative abundance) of Holstein $\times$ Gyr cows fed ad libitum or maintenance at different days of gestation

\begin{tabular}{|c|c|c|c|c|c|c|c|c|c|c|c|c|}
\hline \multirow[b]{2}{*}{ Gene } & \multicolumn{2}{|c|}{ Feeding regimen } & \multirow[b]{2}{*}{ SEM } & \multicolumn{4}{|c|}{ Day of gestation } & \multirow[b]{2}{*}{ SEM } & \multicolumn{4}{|c|}{$P$-value ${ }^{1}$} \\
\hline & Ad libitum & Maintenance & & 139 & 199 & 241 & 268 & & $\mathrm{FR}$ & DG & $\mathrm{FR} \times \mathrm{DG}$ & Sex \\
\hline ANGPT2 & 0.004 & 0.006 & 0.0001 & 0.003 & 0.005 & 0.006 & 0.004 & 0.0010 & 0.06 & 0.12 & 0.64 & 0.87 \\
\hline$F G F 2$ & 0.010 & 0.023 & 0.0015 & 0.008 & 0.017 & 0.023 & 0.020 & 0.0010 & $<0.01$ & $<0.01$ & $<0.01$ & 0.64 \\
\hline Ad libitum & - & - & - & $0.009^{\mathrm{a}, \mathrm{A}}$ & $0.011^{\mathrm{a}, \mathrm{B}}$ & $0.012^{\mathrm{a}, \mathrm{B}}$ & $0.010^{\mathrm{a}, \mathrm{B}}$ & 0.0034 & - & - & - & - \\
\hline Maintenance & - & - & - & $0.006^{\mathrm{b}, \mathrm{A}}$ & $0.023^{\mathrm{a}, \mathrm{A}}$ & $0.034^{\mathrm{a}, \mathrm{A}}$ & $0.031^{\mathrm{a}, \mathrm{A}}$ & 0.0034 & - & - & - & - \\
\hline$P$-value & - & - & - & 0.44 & 0.02 & $<0.01$ & $<0.01$ & - & - & - & - & - \\
\hline NOS3 & 0.004 & 0.009 & 0.0006 & 0.004 & 0.007 & 0.008 & 0.008 & 0.0009 & $<0.01$ & $<0.01$ & 0.08 & 0.36 \\
\hline Ad libitum & - & - & — & $0.004^{\mathrm{a}, \mathrm{A}}$ & $0.004^{\mathrm{a}, \mathrm{B}}$ & $0.005^{\mathrm{a}, \mathrm{B}}$ & $0.005^{\mathrm{a}, \mathrm{B}}$ & 0.0012 & - & - & - & - \\
\hline Maintenance & - & - & - & $0.004^{\mathrm{b}, \mathrm{A}}$ & $0.010^{\mathrm{a}, \mathrm{A}}$ & $0.011^{\mathrm{a}, \mathrm{A}}$ & $0.011^{\mathrm{a}, \mathrm{A}}$ & 0.0012 & - & - & - & - \\
\hline$P$-value & - & - & - & 0.89 & 0.06 & 0.04 & 0.05 & - & - & - & - & - \\
\hline$V E G F A$ & 0.091 & 0.180 & 0.0085 & 0.052 & 0.098 & 0.204 & 0.188 & 0.0133 & $<0.01$ & $<0.01$ & $<0.01$ & 0.56 \\
\hline Ad libitum & - & - & - & $0.057^{\mathrm{a}, \mathrm{A}}$ & $0.126^{\mathrm{a}, \mathrm{A}}$ & $0.088^{\mathrm{a}, \mathrm{B}}$ & $0.093^{\mathrm{a}, \mathrm{B}}$ & 0.0120 & - & - & - & - \\
\hline Maintenance & - & - & - & $0.046^{\mathrm{b}, \mathrm{A}}$ & $0.069^{\mathrm{b}, \mathrm{A}}$ & $0.320^{\mathrm{a}, \mathrm{A}}$ & $0.283^{\mathrm{a}, \mathrm{A}}$ & 0.0162 & - & - & - & - \\
\hline$P$-value & - & - & - & 0.80 & 0.12 & $<0.01$ & $<0.01$ & - & - & - & - & - \\
\hline$V E G F B$ & 0.263 & 0.404 & 0.0266 & 0.292 & 0.351 & 0.368 & 0.321 & 0.0395 & $<0.01$ & 0.49 & 0.33 & 0.45 \\
\hline GUCY1B3 & 0.003 & 0.005 & 0.0003 & 0.003 & 0.004 & 0.005 & 0.004 & 0.0005 & $<0.01$ & 0.01 & $<0.01$ & 0.59 \\
\hline Ad libitum & - & - & - & $0.003^{\mathrm{a}, \mathrm{A}}$ & $0.005^{\mathrm{a}, \mathrm{A}}$ & $0.002^{\mathrm{a}, \mathrm{B}}$ & $0.003^{\mathrm{a}, \mathrm{B}}$ & 0.0007 & - & - & - & - \\
\hline Maintenance & - & - & - & $0.003^{\mathrm{c}, \mathrm{A}}$ & $0.004^{\mathrm{bc}, \mathrm{A}}$ & $0.008^{\mathrm{a}, \mathrm{A}}$ & $0.006^{\mathrm{ab}, \mathrm{A}}$ & 0.0007 & - & - & - & - \\
\hline$P$-value & - & - & - & 0.99 & 0.98 & 0.07 & 0.07 & - & - & - & - & - \\
\hline HIFA 1 & 0.003 & 0.009 & 0.001 & 0.004 & 0.004 & 0.009 & 0.008 & 0.0014 & $<0.01$ & 0.03 & $<0.01$ & 0.85 \\
\hline Ad libitum & - & - & - & $0.004^{\mathrm{a}, \mathrm{A}}$ & $0.004^{\mathrm{a}, \mathrm{A}}$ & $0.003^{\mathrm{a}, \mathrm{B}}$ & $0.003^{\mathrm{a}, \mathrm{B}}$ & 0.0019 & - & - & - & - \\
\hline Maintenance & - & - & - & $0.003^{\mathrm{b}, \mathrm{A}}$ & $0.004^{\mathrm{b}, \mathrm{A}}$ & $0.015^{\mathrm{a}, \mathrm{A}}$ & $0.012^{\mathrm{a}, \mathrm{A}}$ & 0.0019 & - & - & - & - \\
\hline$P$-value & - & - & - & 0.89 & 0.92 & 0.02 & 0.02 & - & - & - & - & - \\
\hline
\end{tabular}

A,B Means within a column with different superscripts differ $(P \leq 0.10)$.

$\stackrel{{ }_{n}}{{ }^{1} \mathrm{FR}}=$ feeding regimen main effects; $\mathrm{DG}=$ day of gestation main effects; $\mathrm{FR} \times \mathrm{DG}=$ interaction between feeding regimen and day of gestation; sex $=$ sex of fetus main effects. No interaction was observed between feeding regimen and sex $(P \geq 0.10)$, day of gestation and sex $(P \geq 0.10)$, and feeding regimen, day of gestation, and sex $(P \geq 0.10)$. 


\section{DISCUSSION}

\section{Utero and Placental Characteristics}

Wallace et al. (2001) evaluated adolescent ewes that were fed moderate or high amount of feed and observed that placenta mass was heavier in those that were fed moderate amounts. Although the mass of placenta and fetus were positively correlated in both groups, the placenta was more affected than the fetus in the overnourished group, thereby leading to a significant difference in the fetal:placenta mass ratio. Although fetal organogenesis is largely complete during early gestation, exponential growth of the fetus is limited to the last third of pregnancy (Redmer et al., 2004), beginning around d 200 and ending around d 280 in Holstein $\times$ Gyr dairy cows (Rotta et al., 2015a). Thus, approximately $90 \%$ of fetal growth occurs during the last third of pregnancy. However, in this study, we observed that in AL-fed cows, the majority of placenta growth occurred at $199 \mathrm{~d}$ of gestation, at which point the placenta achieved its maximum weight, which is based on the fact that the mass of placenta at d 241 and 268 was similar to that at d 199 of gestation. Thus, the fetus has obtained about $10 \%$ of its eventual birth weight by the time the placenta has reached its maximal size (Redmer et al., 2004). However, when considering MLfed cows, the growth pattern of placenta was different because it continued to grow until d 268. Thus, feeding cows the ML diet resulted in a different growth pattern of placenta, which coincides with the greater nutrient requirements of the gravid uterus (Ferrel et al., 1976).

The number of placentomes varies widely between individual cows. Mossman (1987) reported that the number of placentomes varied from around 50 to 175 per uterus, whereas Laven and Peters (2001) reported values ranging from 40 to 120 placentomes. The latter authors reported that the mean number of placentomes ranged from just over 50 per uterus in pregnancies of less than $71 \mathrm{~d}$ to more than 70 in pregnancies of more than $191 \mathrm{~d}$ of gestation. Data from other ruminants are inconclusive as to whether this is a real effect or not. Abdel Raouf and Badawi (1966), reported that in water buffalo, mean placentome number increased from early to late gestation but in sheep and yak, day of gestation appeared to have no significant effect on placentome number (Redmer et al., 2009; Liu et al., 2010). This is the first study evaluating the effect of DG and FR in Holstein $\times$ Gyr cows, and our results suggest that the Gyr breed may increase the number of placentomes. Previous studies with Holstein cattle noted that the placentome number is about 100 units. However, our study found values about 2- to 3-fold greater for placentome units in Holstein $\times$ Gyr. Even though we did not test the influence of breed on placentome number, our results give us reason to suggest that use of the Gyr breed in crossbreeding with Holstein animals may explain the increased placentome number.

The heavier placentome expressed as grams per kilogram of EBW in ML-fed cows may have resulted in a greater uterine blood flow and umbilical blood flow to the fetus. Absolute blood flow to the myometrium increases in proportion to placentome mass, whereas relative uterine blood flow may fluctuate and decrease somewhat (Rosenfeld et al., 1974; Bjellin et al., 1975) or remain constant (Ford et al., 1984; Dowell and Kauer, 1997) during pregnancy. Wallace et al. (2002, 2003) observed that a heavier placentome is responsible for an increase in both uterine and umbilical blood flow in sheep and adult ewes. Thus, the greater uterine and umbilical blood flow results in greater nutrient transfer to the fetus, thereby avoiding fetal injury in ML-fed cows. Those authors also reported that animals that are fed a moderate amount of feed presented with heavier placentome than those fed a high amount of feed. Thus, the results obtained in the present experiment agree with those reported by Wallace et al. (2002, 2003), because we can associate results based on a moderate amount of feed with data from ML-fed cows (approximately $0.30 \mathrm{~kg} / \mathrm{d}$ ADG), and results from cows fed high amounts would associate with those from AL-fed cows (approximately $1.10 \mathrm{~kg} / \mathrm{d}$ ADG).

For ML-fed cows, a different placentome adaptation occurred. This may be related to the greater nutritional transfer capacity of these cows to avoid fetal growth retardation. The greater placentome units found at 268 d of gestation in ML-fed cows may be explained by the higher nutrient requirements for gestation during this period (NRC, 2001). Maternal overfeeding is associated with altered fetal development and long-term adverse consequences on the progeny (George et al., 2010; Reynolds and Caton, 2012).

\section{Placental Gene Expression}

The increase in the gene expression of IGFR1 and IGFR2 occurred when the nutritional requirements were greater (NRC, 2001). We suggest that this is evidence that IGFR1 and IGFR2 are sensitive in placentome alterations in the maternal metabolic environment and hypothesize that an alternative endocrine factor may regulate the growth of fetuses from feed-restricted cows. To provide the fetus and newborn with sufficient energy and nutrients, the pregnant dam undergoes several physiological, metabolic, and endocrine adaptations (Prentice et al., 1995; Olausson and Sohlstrom, 2003). Changes in the insulin-like growth factor receptor (IGFR) system are one type of adaptation. Several 
studies have demonstrated the importance of IGFR1 and IGFR2 for gestation (DeChiara, et al., 1990; Constância et al., 2002; Fowden, 2003), but none of these studies examined effects in dairy cattle.

Vascular endothelial growth factor A acts locally in the bovine placenta to modulate steroidogenesis during gestation and can be considered an important regulator of placenta development and function (Sousa et al., 2012). Moreover, it is responsible for regulating cell growth and differentiation, as well as the control of angiogenesis and neovascularization in organs and tissues (Pfarrer et al., 2006). Thus, the greater its concentration in an animal, the greater the potential for vascularization; therefore, we can assume that more nutrients are transferred from the cow to the fetus.

The greatest values of VEGFA at 241 d of gestation observed in this study may be explained, in part, by the greater nutrient requirements during the final phase of gestation, and because ML-fed cows had a lower DMI (Rotta et al., 2015b) than AL-fed cows. Thus, ML-fed cows may have improved their vascular efficiency in transferring more nutrients to the fetus. When cells are deprived of oxygen, they increase their production of $V E G F-A 5 ; V E G F-A$ mediates the growth of new blood vessels from pre-existing vessels by binding to the cell surface receptors VEGFR1 and VEGFR2, 2 tyrosine kinases located in endothelial cells of the cardiovascular system. These 2 receptors act through different pathways to contribute to endothelial cell proliferation and migration, and formation of tubular structures (Huusko et al., 2010).

Vascular endothelial growth factor B is related to embryonic angiogenesis (Claesson-Welsh, 2008) and endothelial cell growth, particularly in muscle (Olofsson et al., 1996). Thus, the greater values of $V E G F B$ expression in ML-fed cows suggest greater angiogenesis and cell growth in the fetus. In contrast to VEGFA, $V E G F B$ plays a less pronounced role in the vascular system: whereas VEGFA is important for the formation of blood vessels, such as during development or in pathological conditions, $V E G F B$ seems to play a role only in the maintenance of newly formed blood vessels during pathological conditions (Zhang et al., 2009).

Expression of ANGPT2 is associated with angiogenesis and vessel maturation (Li et al., 2013). Nitric oxide has also been implicated as a mediator of $V E G F$ - (Ziche et al., 1997; Parenti et al., 1998) and FGF2- (Babaei et al., 1998) induced angiogenesis; $V E G F$ is a major regulator of placental angiogenesis and may play a significant role in the upregulation of growth signaling pathways in cotyledons under maternal nutrient restriction (Reynolds et al., 2005). Other growth factors may also be responsible for the upregulation of these growth signaling pathways.
The protein encoded by HIF1 is a bHLH-PAS transcription factor found in mammalian cells growing at low oxygen concentrations. It plays an essential role in cellular and systemic responses to hypoxia (Ratcliffe, 2002). Thus, the greater expression of HIF1 observed in ML-fed animals during the final gestation period may suggest that a decrease in oxygen concentration is necessary to increase the expression of HIF1.

\section{CONCLUSIONS}

Feeding regimen alters growth of placenta, cotyledon, caruncle, and placentome in Holstein $\times$ Gyr cows. Greater expression of IGFR1 and IGFR2 was observed in ML-fed cows, and the reduced nutrient intake of those cows did not affect the fetal weight, probably because genes related to the angiogenic process were more expressed in ML-fed cows than AL-fed cows, suggesting that ML-fed cows had more placenta vascularity. This finding suggests that ML-fed cows have physiological ways to compensate low levels of nutrients that otherwise could impair the development of their fetuses.

\section{REFERENCES}

Abdel-Raouf, M., and H. M. Badawi. 1966. Morphological study of uterine caruncles in Egyptian buffalo cows. Zentralbl. Veterinarmed. [C] 13:252-263.

AOAC International. 2000. Official Methods of Analysis. 17th ed. AOAC International, Arlington, VA.

Babaei, S., K. Teichert-Kuliszewska, J. C. Monge, F. Mohamed, M. P. Bendeck, and D. J. Stewart. 1998. Role of nitric oxide in the angiogenic response in vitro to basic fibroblast growth factor. Circ. Res. 82:1007-1015.

Bjellin, L., P. O. Sjoquist, and A. M. Carter. 1975. Uterine, maternal placental and ovarian blood flow throughout pregnancy in the guinea pig. Z. Geburtshilfe Perinatol. 179:179-187.

Borowicz, P. P., D. R. Arnold, M. L. Johnson, A. T. Grazul-Bilska, D. A. Redmer, and L. P. Reynolds. 2007. Placental growth throughout the last two thirds of pregnancy in sheep: vascular development and angiogenic factor expression. Biol. Reprod. 76:259-267. http://dx.doi.org/10.1095/biolreprod.106.054684.

Brasil. 1997. Regulamento da Inspeção Industrial e Sanitária de Produtos de Origem Animal [Food of animal origin sanitary and industry inspection]. Ministério da Agricultura, Pecuária e Abastecimento, Brasilia, Brazil.

Carmeliet, P., V. Ferreira, G. Breier, S. Pollefeyt, L. Klenkens, M. Gertsenstein, M. Fahrig, A. Vandenhoeck, K. Harpal, C. Eberhardt, C. Declercq, J. Pawling, L. Moons, D. Collen, W. Risau, and A. Nagy. 1996. Abnormal blood vessel development and lethality in embryos lacking a single VEGF allele. Nature 380:435439. http://dx.doi.org/10.1038/380435a0.

Claesson-Welsh, L. 2008. VEGF-B taken to our hearts: Specific effect of VEGF-B in myocardial ischemia. Arterioscler. Thromb. Vasc. Biol. 28:1575-1576. http://dx.doi.org/10.1161/ ATVBAHA.108.170878.

Constância, M., M. Hemberger, J. Hughes, W. Dean, A. FergusonSmith, R. Fundele, F. Steward, G. Kelsey, A. L. Fowden, C. Sibley, and W. Reik. 2002. Placental-specific IGF-II is a major modulator of placental and fetal growth. Nature 417:945-948. http://dx.doi. org/10.1038/nature00819.

DeChiara, T. M., E. J. Robertson, and A. Efstratiadis. 1990. A growthdeficient phenotype in heterozygous mice carry an insulin-like 
growth factor II gene disrupted by targeting. Nature 345:78-80. http://dx.doi.org/10.1038/345078a0.

Dowell, R. T., and C. D. Kauer. 1997. Maternal hemodynamics uteroplacental blood flow throughout gestation in conscious rat. Methods Find. Exp. Clin. Pharmacol. 19:613-625.

Ferrara, N., K. Carver-Moore, H. Chen, M. Dowd, L. Lu, K. S O'Shea, L. Powell-Braxton, K. J. Hillan, and M. W. Moore. 1996. Heterozygous embryonic lethality induced by targeted inactivation of the VEGF gene. Nature 380:439-442. http://dx.doi. org $/ 10.1038 / 380439 a 0$

Ferrel, C. L., W. N. Garret, and N. Hinman. 1976. Estimation of body composition in pregnant and nonpregnant heifers. J. Anim. Sci. 42:1158-1166

Ford, S. P. 2000. Cotyledonary placenta. Pages 730-738 in Encyclopedia of Reproduction. Vol. 1. E. Knobil and J. D. Neil, ed. Academic Press, San Diego, CA.

Ford, S. P., L. P. Reynolds, and C. L. Ferrell. 1984. Blood flow, steroid secretion and nutrient uptake of the gravid uterus during the periparturient period in sows. J. Anim. Sci. 59:1085-1091.

Fowden, A. L. 2003. The insulin-like growth factors and feto-placental growth. Placenta 24:803-812. http://dx.doi.org/10.1016/S01434004(03)00080-8.

George, L. A., A. B. Uthlaut, N. M. Long, L. Zhang, Y. Ma, D. T. Smith, P. W. Nathanielsz, and S. P. Ford. 2010. Different levels of overnutrition and weight gain during pregnancy have differential effects on fetal growth and organ development. Reprod. Biol. Endocrinol. 8:75. http://dx.doi.org/10.1186/1477-7827-8-75.

Godfrey, K. M. 2002. The role of the placenta in fetal programming - A review. Placenta 23(Suppl. A):S20-27. http://dx.doi. org/10.1053/plac.2002.0773.

Godfrey, K. M., and D. J. Barker. 2000. Fetal nutrition and adult disease. Am. J. Clin. Nutr. 71:1344S-1352S.

Huusko, J., M. Merentie, M. H. Dijkstra, M. M. Ryhanen, H. Karvinen, T. T. Rissanen, M. Vanwildemeersch, M. Hedman, J. Lipponen, S. E. Heinonen, U. Eriksson, M. Shibuya, and S. Yla-Herttuala. 2010. The effects of VEGF-R1 and VEGF-R2 ligands on angiogenic responses and left ventricular function in mice. Cardiovasc. Res. 86:122-130. http://dx.doi.org/10.1093/cvr/cvp382.

IBGE. 2009. Censo Agropecuario. Accessed Dec. 8, 2014. http://www. ibge.gov.br/home/estatistica/economia/agropecuaria/censoagro/.

Laven, R. A., and A. R. Peters. 2001. Gross morphometry of the bovine placentome during gestation. Reprod. Domest. Anim. 36:289-296.

Laviola, L., S. Perrini, G. Belsanti, A. Natalicchio, C. Montrone, A. Leonardini, A. Vimercati, M. Scioscia, L. Selvaggi, R. Giorgino, P. Greco, and F. Giorgino. 2005. Intrauterine growth restriction in humans is associated with abnormalities in placental insulin-like growth factor signaling. Endocrinology 146:1498-1505.

Li, C., C. J. Sun, J. C. Fan, N. Geng, C. H. Li, J. Liai, K. Mi, G Q. Zhu, H. Ma, Y. F. Song, Y. L. Tang, and Y. Chen. 2013. Angiopoietin-2 expression is correlated with angiogenesis and overall survival in oral squamous cell carcinoma. Med. Oncol. 30:571 http://dx.doi.org/10.1007/s12032-013-0571-2.

Liu, B., Y. Cui, B. Yang, J. Fan, Z. Zhao, and S. Yu. 2010. Morphometric analysis of yak placentomes during gestation. Anat. Rec. 293:1873-1879.

Livak, K. J., and T. D. Schmittigen. 2001. Analysis of relative gene expression data using real-time quantitative PCR and the $2 \mathrm{DDCt}$ method. Methods 25:402-408. http://dx.doi.org/10.1006/ meth.2001.1262.

Mossman, H. W. 1987. Vertebrate Fetal Membranes. MacMillan, Houndmills, UK.

NRC. 2001. Nutrient Requirements of Dairy Cattle. 7th rev. ed. Natl. Acad. Press, Washington, DC.

Olausson, H., and A. Sohlstrom. 2003. Effects of food restriction and pregnancy on the expression of insulin-like growth factors-I and -II in tissues from guinea pigs. J. Endocrinol. 179:437-445. http:// dx.doi.org/10.1677/joe.0.1790427.

Olofsson, B., K. Pajusola, A. Kaipainen, G. von Euler, V. Joukov, O. Sakselas, A. Orpanat, R. F. Petterson, K. Alitalo, and U. Eriksson.
1996. Vascular endothelial growth factor B, novel growth factor for endothelial cells. Proc. Natl. Acad. Sci. USA 93:2576-2581.

Parenti, A., L. Morbidelli, X. L. Cui, J. G. Douglas, J. D. Hood, H. J. Granger, F. Ledda, and M. Ziche. 1998. Nitric oxide is an upstream signal of vascular endothelial growth factor-induced extracellular signal-regulated kinase $1 / 2$ activation in postcapillary endothelium. J. Biol. Chem. 273:4220-4226.

Pfaffl, M. W. 2001. A new mathematical model for relative quantification in real-time RT-PCR. Nucleic Acids Res. 29:e45. http:// dx.doi.org/10.1093/nar/29.9.e45.

Pfarrer, C. D., S. D. Ruziwa, H. Winther, H. Callesen, R Leiser, D. Schams, and V. Dantzer. 2006. Localization of vascular endothelial growth factor (VEGF) and its receptors VEGFR-1 and VEGFR-2 in bovine placentomes from implantation until term. Placenta 27:889-898. http://dx.doi.org/10.1016/j.placenta.2005.09.004.

Prentice, A. M., S. D. Poppitt, G. R. Goldberg, and A. Prentice. 1995 Adaptive strategies regulating energy balance in human pregnancy. Hum. Reprod. Update 1:149-161. http://dx.doi.org/10.1093/ humupd/1.2.149.

Ratcliffe, P. J. 2002. From erythropoietin to oxygen: Hypoxia-inducible factor hydroxylases and the hypoxia signal pathway. Blood Purif. 20:445-450. http://dx.doi.org/10.1159/000065201.

Redmer, D. A., J. S. Luther, J. S. Milne, R. P. Aitken, M. L. Johnson, P. P. Borowicz, M. A. Borowicz, L. P. Reynolds, and J. M. Wallace. 2009. Fetoplacental growth and vascular development in overnourished adolescent sheep at day 50,90 and 130 of gestation. Reproduction 137:749-757.

Redmer, D. A., J. M. Wallace, and L. P. Reynolds. 2004. Effect of nutrient intake during pregnancy on fetal and placental growth and vascular development. Domest. Anim. Endocrinol. 27:199-217. http://dx.doi.org/10.1016/j.domaniend.2004.06.006.

Reynolds, L. P., P. P. Borowicz, K. A. Vonnahme, M. L. Johnson, A T. Grazul-Bilska, D. A. Redmer, and J. S. Caton. 2005. Placental angiogenesis in sheep models of compromised pregnancy. J. Physiol. 565:43-58.

Reynolds, L. P., and J. S. Caton. 2012. Role of the pre- and postnatal environment in developmental programming of health and productivity. Mol. Cell. Endocrinol. 354:54-59. http://dx.doi. org/10.1016/j.mce.2011.11.013.

Reynolds, L. P., and D. A. Redmer. 1992. Growth and microvascular development of the uterus during early pregnancy in ewes. Biol. Reprod. 47:698-708. http://dx.doi.org/10.1095/biolreprod 47.5.698

Rosenfeld, C. R., F. H. Morriss, E. L. Jr Makowski, G. Meschia, and F. C. Battaglia. 1974. Circulatory changes in the reproductive tissues of the ewes during pregnancy. Gynecol. Invest. 5:252-268.

Rotta, P. P., S. C. Valadares Filho, T. R. Santos, L. F. Costa e Silva, T. E. Engle, M. I. Marcondes, M. M. Campos, A. C. B. Menezes, and A. A. G. Lobo. 2014a. Effects of stage of gestation and feeding regimen in Holstein $\times$ Gyr cows: II. Maternal and feral visceral organ mass. J. Dairy Sci. 98:3211-3223. 10.3168/jds.2014-8282.

Rotta, P. P., S. C. Valadares Filho, T. R. Santos, L. F. Costa e Silva, T. E. Engle, M. I. Marcondes, F. S. Machado, F. A. C. Villadiego, and L. H. R. Silva. 2014b. Effects of stage of gestation and feeding regimen in Holstein $\times$ Gyr cows: I. Apparent total-tract digestibility, nitrogen balance, microbial protein supply, and fat deposition. J. Dairy Sci. 98:3197-3210. 10.3168/jds.2014-8280.

Shalaby, F., J. Rossant, T. P. Yamaguchi, M. Gertsenstein, X. F. Wu M. L. Breitman, and A. C. Schuh. 1995. Failure of blood-island formation and vasculogenesis in Flk-1-deficient mice. Nature 376:62-66. http://dx.doi.org/10.1038/376062a0.

Sousa, L. M. M. C., D. B. Campos, V. U. Fonseca, P. Viau, J. R. Kfoury Jr., C. A. Oliveira, M. Binelli, J. Burantini, and P. C. Papa. 2012. Vascular endothelial growth factor A (VEGFA) modulates bovine placenta steroidogenesis in vitro. Placenta 33:788794. http://dx.doi.org/10.1016/j.placenta.2012.07.009.

Vandesompele, J., K. De Preter, F. Pattyn, B. Poppe, N. Van Roy, A De Paepe, and F. Speleman. 2003. Accurate normalization of realtime quantitative RT-PCR data by geometric averaging of mul- 
tiple internal control genes. Genome Biol. 18:RESEARCH0034. http://dx.doi.org/10.1186/gb-2002-3-7-research0034.

Vonnahme, K. A., B. W. Hess, T. R. Hansen, R. J. McCormick, D. C. Rule, G. E. Moss, W. J. Murdoch, M. J. N. Nijland, D. C. Skinner, P. W. Nathanielsz, and S. P. Ford. 2003. Maternal undernutrition from early- to mid-gestation leads to growth retardation, cardiac ventricular hypertrophy, and increased liver weight in the fetal sheep. Biol. Reprod. 69:133-140. http://dx.doi.org/10.1095/biolreprod.102.012120.

Vonnahme, K. A., C. O. Lemley, P. Shukla, and S. T. O'Rourke. 2013. 2011 and 2012 Early Careers Achievement Awards: Placental programming: How the maternal environment can impact placental function. J. Anim. Sci. 91:2467-2480. http://dx.doi.org/10.2527/ jas.2012-5929.

Wallace, J. M., D. A. Bourke, R. P. Aitken, N. Leitch, and W. W. Hay Jr. 2002. Blood flows and nutrient uptakes in growth restricted pregnancies induced by overnourishing adolescent sheep. Am. J. Physiol. Regul. Integr. Comp. Physiol. 282:R1027-R1036. http:// dx.doi.org/10.1152/ajpregu.00465.2001.

Wallace, J. M., D. A. Bourke, P. Da Silva, and R. P. Aitken. 2001. Nutrient partitioning during adolescent pregnancy. Reproduction 122:347-357. http://dx.doi.org/10.1530/rep.0.1220347.

Wallace, J. M., J. S. Milne, N. Leitch, and R. P. Aitken. 2003. Overnourishing singleton bearing adult ewes stimulates adiposity but does not influence nutrient partitioning to the gravid uterus.
Pediatr. Res. 6:38-42. http://dx.doi.org/10.1203/00006450197201000-00006.

Zhang, F., Z. Tang, X. Hou, J. Lennartsson, Y. Li, A. W. Koch, P. Scotney, C. Lee, P. Arjunan, L. Dong, A. Kumar, T. T. Rissanen, B. Wang, N. Nagai, P. Fons, R. Fariss, Y. Zhang, E. Wawrousek, G. Tansey, J. Raber, G. H. Fong, H. Ding, D. A. Greenberg, K. G. Becker, J. M. Herbert, A. Nash, S. Yla-Herttuala, Y. Cao, R J. Watts, and X. Li. 2009. VEGF-B is dispensable for blood vessel growth but critical for their survival, and VEGF-B targeting inhibits pathological angiogenesis. Proc. Natl. Acad. Sci. USA 106:6152-6157. http://dx.doi.org/10.1073/pnas.0813061106.

Zhu, M. J., M. Du, and S. P. Ford. 2014. Impacts of maternal obesity on placental and gut inflammation and health. J. Anim. Sci. 92:1840-1849. http://dx.doi.org/10.2527/jas.2013-7106.

Zhu, M. J., M. Du, B. W. Hess, W. J. Means, P. W. Nathaniels, and S. P. Ford. 2007. Maternal nutrient restriction upregulates growth signaling pathways in the cotyledonary artery of cows' placentomes. Placenta 28:361-368. http://dx.doi.org/10.1016/j. placenta.2006.04.005.

Ziche, M., L. Morbidelli, R. Choudhuri, H. T. Zhang, S. Donnini, H. J. Granger, and R. Bicknell. 1997. Nitric oxide synthase lies downstream from vascular endothelial growth factor-induced but not basic fibroblast growth factor-induced angiogenesis. J. Clin. Invest. 99:2625-2634. 